\title{
First-of-a-Kind Control Room Modernization Project Plan
}

\author{
Ken D. Thomas
}

February 2016

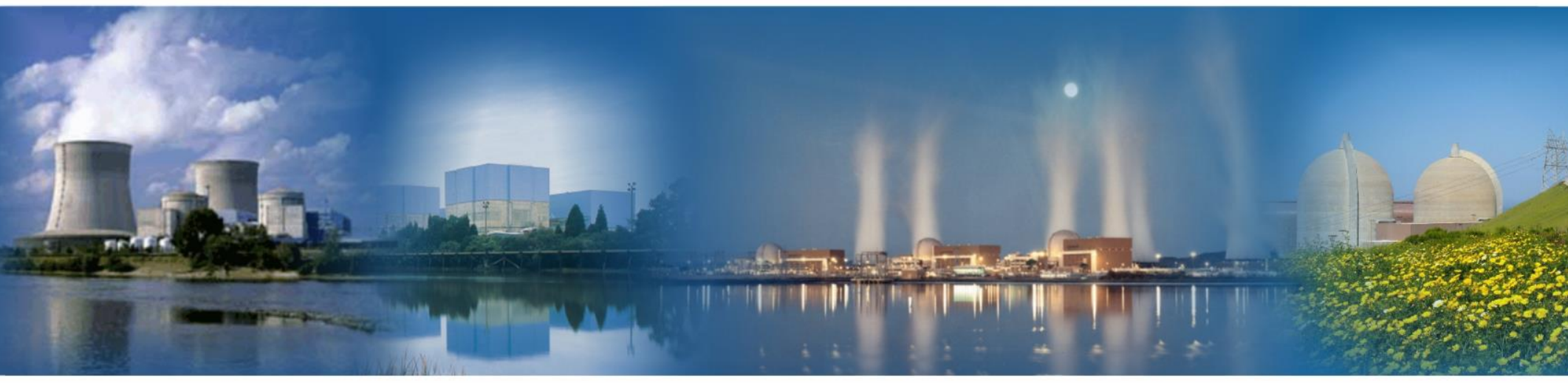

U.S. Department of Energy

Office of Nuclear Energy 


\section{DISCLAIMER}

This information was prepared as an account of work sponsored by an agency of the U.S. Government. Neither the U.S. Government nor any agency thereof, nor any of their employees, makes any warranty, expressed or implied, or assumes any legal liability or responsibility for the accuracy, completeness, or usefulness, of any information, apparatus, product, or process disclosed, or represents that its use would not infringe privately owned rights. References herein to any specific commercial product, process, or service by trade name, trade mark, manufacturer, or otherwise, does not necessarily constitute or imply its endorsement, recommendation, or favoring by the U.S. Government or any agency thereof. The views and opinions of authors expressed herein do not necessarily state or reflect those of the U.S. Government or any agency thereof. 


\title{
First-of-a-Kind Control Room Modernization Project Plan
}

\author{
Ken D. Thomas
}

February 2016

Idaho National Laboratory Idaho Falls, Idaho 83415

http://www.inl.gov

Prepared for the

U.S. Department of Energy

Office of Nuclear Energy

Under DOE Idaho Operations Office

Contract DE-AC07-05ID14517 



\begin{abstract}
To mitigate the substantial technical, financial, and regulatory risks in a nuclear plant control room modernization, the U.S. Department of Energy's Light Water Reactor Sustainability (LWRS) Program will partner with Arizona Public Service (APS) Company in a First-of-a-Kind (FOAK) Control Room Modernization Project. This project will assist this first-mover nuclear utility in addressing legacy analog technology issues of reliability, obsolescence, as well as to enable improved operator and plant

performance. This will also demonstrate the feasibility and benefits of control room modernization to the commercial nuclear operators, suppliers, and industry support community. This project will be a major step in resolving legacy instrumentation, information, and control issues that potentially impact long-term sustainability of the light water reactor fleet.
\end{abstract}

This project applies advanced tools, methodologies, and facilities in a science-based approach to the validation of engineering and human factors principles for nuclear plant control room modernization. It addresses the required project results and documentation to demonstrate compliance with regulatory requirements.

This project plan describes the collaboration arrangement between the LWRS Program and the APS Palo Verde Nuclear Generating Station. It also describes the role of other collaborators, including the Institute for Energy Technology and the Electric Power Research Institute. Finally, it describes the project tasks that will be conducted in the project, and the deliverable reports that will be developed through these tasks.

This project plan will be updated as new tasks are added and as project milestones are completed. It will serve as an ongoing description on the project both for the project participants and the industry stakeholders. 


\section{CONTENTS}

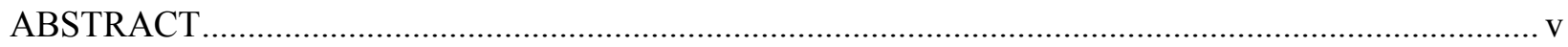

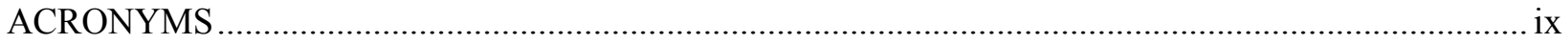

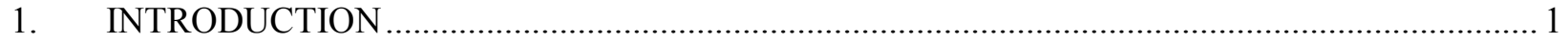

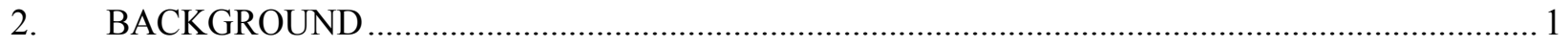

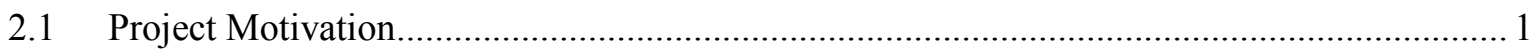

2.2 Control Room Modernization Project .......................................................................... 2

2.3 Partnership with Arizona Public Service Company ............................................................. 3

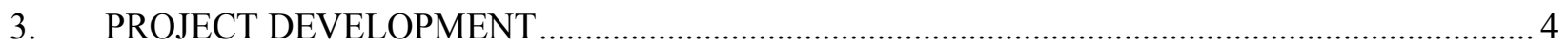

3.1 Cooperative Research and Development Agreement (CRADA) ….................................... 4

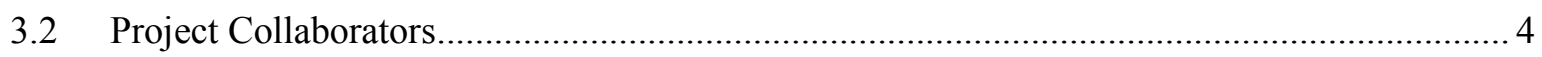

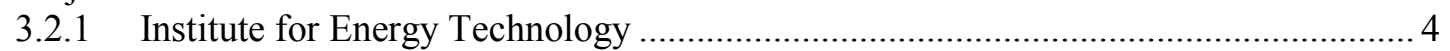

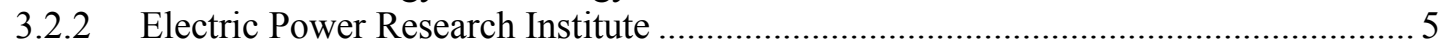

3.2.3 Engineering and Human Factors Consultants ........................................................ 5

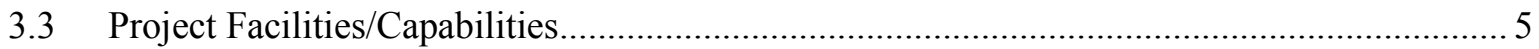

3.3.1 Human System Simulation Laboratory ................................................................. 5

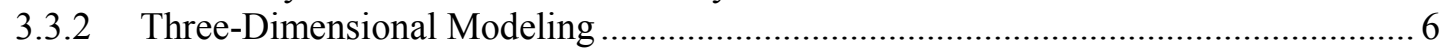

3.3.3 Computer Assisted Virtual Environment .............................................................. 7

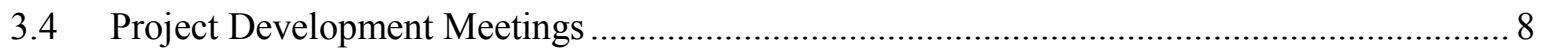

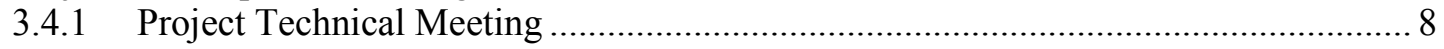

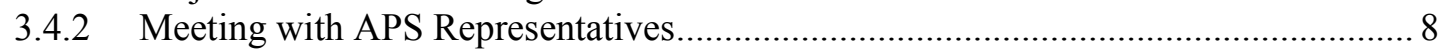

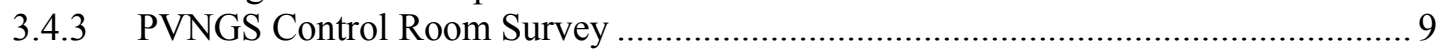

3.4.4 Meeting with Westinghouse Electric Corporation ............................................... 10

3.4.5 Meeting with STARS Alliance ........................................................................... 10

3.4.6 Westinghouse Project Meeting and Project Facilities Orientation............................. 10

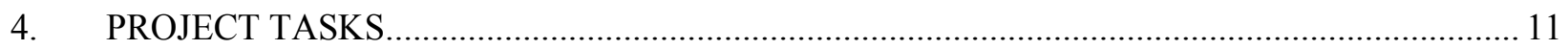

4.1 Task 1: Control Room Baseline Model................................................................................ 11

4.2 Task 2: End-State Concept for a Modernized Control Room .............................................. 11

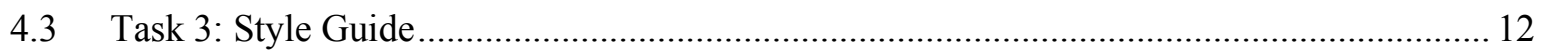

4.4 Task 4: Modernized Control Room Business Case Framework ......................................... 12

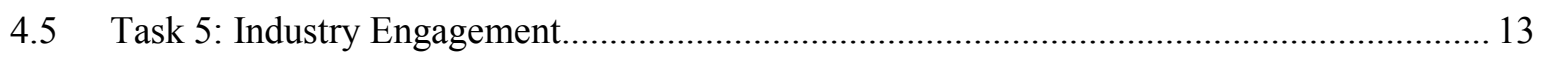

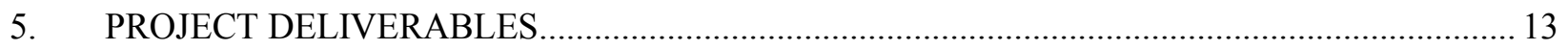

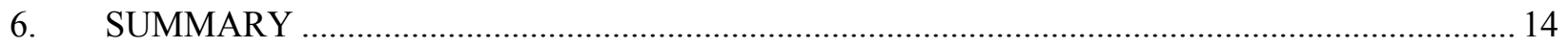

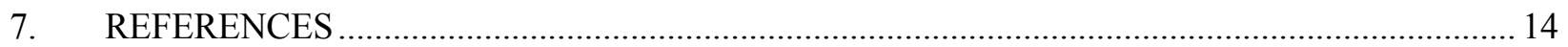




\section{FIGURES}

Figure 1. Human Systems Simulation Laboratory - Reconfigurable Hybrid Control Room Simulator.

Figure 2. 3-D Control Room Model depicting operator vision attributes.................................................. 7

Figure 3. The Computer-Assisted Virtual Environment (CAVE). ......................................................... 7

Figure 4. Project technical meeting resulting in initial designs for the End-State Concept....................... 8

Figure 5. PVNGS representatives participate in a demonstration of project capabilities. ........................ 9

Figure 6. Example of a control board model created from the control room survey data. .........................9

Figure 7. Initial version of a 3-D baseline model of the PVNGS control room....................................... 11

Figure 8. Depiction of possible location of digital displays in the PVNGS control room........................ 12

\section{TABLES}

Table 1. Milestone deliverables. 14 


\section{ACRONYMS}

3-D three-dimensional

APS Arizona Public Service

CAES Center for Advanced Energy Studies

CAVE Computer-Assisted Virtual Environment

CRADA Cooperative Research and Development Agreement

DCS distributed control systems

DOE Department of Energy

EPRI Electric Power Research Institute

FOAK distributed control systems

HSSL Human Systems Simulation Laboratory

IFE Institute for Energy Technology

II\&C Instrumentation, Information, and Control

INL Idaho National Laboratory

KAERI Korean Atomic Energy Research Institute

LWR light water reactor

LWRS Light Water Reactor Sustainability

NPP nuclear power plant

NRC Nuclear Regulatory Commission

PVNGS Palo Verde Nuclear Generating Station

R\&D research and development

SMP Strategic Modernization Program

UWG Utility Working Group 


\section{First-of-a-Kind Control Room Modernization Project Plan}

\section{INTRODUCTION}

This report describes the project plan for the First-of-a-Kind (FOAK) Control Room Modernization Project being conducted under the Department of Energy's (DOE) Light Water Reactor Sustainability Program.

The Light Water Reactor Sustainability (LWRS) Program is a research and development (R\&D) program sponsored by DOE, which is conducted in close collaboration with industry to provide the technical foundations for licensing and managing the long-term, safe, and economical operation of current nuclear power plants. The LWRS Program serves to help the U.S. nuclear industry adopt new technologies and engineering solutions that facilitate the continued safe operation of the plants and extension of the current operating licenses.

Within the LWRS Program, the Advanced Instrumentation, Information, and Control (II\&C) Systems Technologies Pathway conducts targeted R\&D to address aging and reliability concerns with the legacy instrumentation and control and related information systems of the U.S. operating light water reactor (LWR) fleet. This extends to the information and technology applications that support the wide spectrum of plant support activities. The II\&C Pathway is conducted by Idaho National Laboratory (INL).

The program has two over-arching goals: (1) to ensure that legacy analog II\&C systems are not life-limiting issues for the LWR fleet, and (2) to implement digital II\&C technology in a manner that enables broad innovation and business improvement in the nuclear power plant operating model. These goals are addressed through a series of pilot projects to develop and demonstrate new technologies that can effect transformative change in the operations and support of nuclear plants.

Pilot projects have been defined to develop the needed technologies and methodologies to achieve performance improvement through incremental control room enhancements as nuclear plant II\&C systems are replaced with digital upgrades. These pilot projects are targeted at realistic opportunities to improve control room performance with the types of digital technologies most commonly being implemented, notably distributed control systems (DCS) and plant computer upgrades.

\section{BACKGROUND}

\subsection{Project Motivation}

For the current nuclear operating fleet, control rooms consist of an expansive set of control boards to accommodate the hundreds of discrete controls and indications required by analog control technologies. The control rooms are also ringed with overhead alarm panels, consisting of hundreds of individual alarm windows each dedicated to a particular alarm condition. The complexity and sheer number of devices in the control room is formidable. Indeed, the legacy control systems present many challenges to the operators, who have admirably overcome them through familiarity and intense training.

Moreover, nuclear utilities are dealing with reliability and obsolescence issues regarding these legacy control systems. They are expensive to maintain and even more expensive to change out when parts can no longer be obtained. These concerns will only grow larger over time.

Today, there is much better technology available for nuclear plant control rooms, having been proven so in other power and process plant applications. Control rooms in conventional power plants (coal, gas, and hydro) have been extensively upgraded by these same utilities. And the process industry has largely gone to all digital control rooms. The new digital control room technologies have resulted in demonstrated benefits in operator performance as well as maintainability. 
Virtually all U.S. operating nuclear plants have undergone some number of digital upgrades over their operating lives, making them hybrid control rooms or ones that employ a mixture of analog and digital technologies. However, in implementing these upgrades, the utilities have largely avoided significant changes to the control room configurations by forcing the operator interface components of these new digital systems into the same form and function as the legacy controls they are replacing. As a result, many of the operator performance benefits that are inherent in these new digital technologies have been foregone.

Following this approach, the business case for upgrading the control rooms of operating nuclear plants has been difficult, made even more so due to the special nature of commercial nuclear power. Extensive safety and regulatory requirements drive the costs of modifications an order of magnitude higher in nuclear plants than in conventional power plants. And there has been uncertainty as to whether efficiency gains in operations can actually result in reduced cost of operations, since staffing levels are driven by a complex set of task requirements and emergency response functions. Finally, it is perceived that there are substantial technical, cost, and regulatory risks in such projects, some of which are beyond the control of the utility.

However, at the same time, the development of a new generation of nuclear plants, and in particular the Westinghouse AP-1000 units being constructed in the U.S., are introducing modernized and more compact control rooms using operator control consoles facing large plant overview displays. Significant advantages for operators are anticipated for these new digital control rooms.

Now the question is whether some of these new technologies can be successfully and economically retrofitted into the conventional controls rooms of the operating fleet to yield the same types of benefits.

The LWRS Program Control Room Modernization Pilot Project was initiated to develop the technologies, tools, and methodologies that will convincingly demonstrate the benefits of a modernized control room in an operating nuclear plant. DOE has recognized that such a project is needed to mitigate these real and perceived concerns in undertaking such projects by collaborating with an industry firstmover to demonstrate the technical feasibility, resulting benefits, and a sound business case.

\subsection{Control Room Modernization Project}

To mitigate the substantial technical, financial, and regulatory risks in control room modernization for operating nuclear plants, DOE is partner with Arizona Public Service (APS) in a FOAK Control Room Modernization Design Project. This program will assist the first-mover nuclear operator in addressing legacy analog technology issues of reliability, obsolescence, as well as to enable improved operator and plant performance. It will also demonstrate the feasibility and benefits of control room modernization to the commercial nuclear operators, suppliers, and industry support community. This project will be a major step in resolving legacy control system that potentially impact long-term sustainability of the LWR fleet.

The DOE LWRS Program - II\&C Pathway commitment will be a significant cost contribution over several years, with similar utility cost-share. In addition, the II\&C Pathway will make commit facilities and expert staff as resources for this project. The II\&C Pathway, with participating collaborators, will work with the utility to develop one or more end-state control room concepts. International and domestic experience will be leveraged in developing the concepts though current associations (Institute for Energy Technology [IFE], Electric Power Research Institute [EPRI], Korean Atomic Energy Research Institute [KAERI], and domestic new builds). DOE facilities at INL will be used to develop and validate the design concepts, including the reconfigurable control room simulator (HSSL), the virtual reality laboratory, and three-dimensional design and ergonomics software.

An optimum End-State Concept will be proposed for conceptual design to determine a cost estimate and work scope for implementing the modernized control room. This End-State Concept will be scoped to take advantage of the capabilities of the digital upgrades for I\&C systems (current and future) to enhance 
the business case for the modernization effort. Finally, a framework for a business case will be developed that captures the cost and operator performance improvements resulting from the modernized control room.

\subsection{Partnership with Arizona Public Service Company}

Arizona Public Service's Palo Verde Nuclear Generating Station (PVNGS) has been a valued partner in LWRS Program pilot projects since 2011, having provided utility requirements input for new technologies and hosting a number of technology demonstrations at their facilities. These include technologies for computer-based procedures, electronic work packages, and outage improvement technologies. In addition, PVNGS has hosted industry meetings of interested utilities and other stakeholders on the various technologies being developed.

In 2015, LWRS Program managers conducted discussions with Mr. Michael Grigsby, PVNGS Assistant Plant Manager, about possible interest in collaborating in a project for control room modernization. Mr. Grigsby in turn conferred with key PVNGS managers and then sponsored some preliminary meetings with representatives of the LWRS Program. These meetings resulted in a willingness of PVNGS to consider a project proposal from the LWRS Program on control room modernization.

In parallel, meetings were held among the leadership in DOE on how such a project could be formulated under the LWRS Program, and what the objectives and outcomes should be. Out of these discussions, a project proposal was developed.

Accordingly, meetings were held at PVNGS on September 10, 2015, between the DOE LWRS Program and PVNGS to discuss potential collaboration in the design of a modernized control room. PVNGS is conducting a Strategic Modernization Program for selected legacy control systems and, because they control system changes will impact the layout of the plants main control boards, there is opportunity to enhance the layout and introduce new technologies that can improve operator performance and enable new operating efficiencies.

PVNGS representatives:

$\begin{array}{ll}\text { Mr. Randy Edington } & \text { Chief Nuclear Officer } \\ \text { Mr. Bob Bement } & \text { Senior Vice President } \\ \text { Mr. Jack Cadogan } & \text { Vice President, Nuclear Engineering } \\ \text { Mr. Chuck Kharrl } & \text { General Plant Manager } \\ \text { Mr. Michael Grigsby } & \text { Assistant Plant Manager } \\ \text { Mr. Panos Paramithas } & \text { Director, Engineering Projects } \\ \text { Mr. John Hernandez } & \text { Supervisor, Digital Projects }\end{array}$

DOE Light Water Reactor Sustainability Program representatives:
Dr. Tom Miller
DOE Deputy Director, Light Water Reactor Technology
Mr. Richard Reister
DOE Federal Program Manager - LWRS Program
Dr. Kathy McCarthy
Director, LWRS Program Technical Integration Office
Dr. Bruce Hallbert
Director, Nuclear Energy Enabling Technologies
Mr. Ken Thomas
Senior Consultant 
The background of the LWRS Program and the motivation of the DOE to sponsor this work were presented to the PVNGS management team. In addition, the capabilities and related experience was presented of the LWRS Program in a similar-type control room upgrade work with other utilities. The proposed scope and activities of the project were outlined in broad terms, recognizing there would need to be flexible to match the requirements and schedule of the PVNGS control system upgrade project.

PVNGS representatives described their objectives and requirements for the Strategic Modernization Program and their urgency in resolving certain technical challenges with their legacy control systems, such as acquiring replacement parts. They stated conditions that would have to be observed in the conduct of such a project, such as not delaying their system upgrade schedule and the need to have a solid business case for control room configuration changes. Both parties were in full agreement with these conditions.

Agreement was reached in these meetings to proceed with the definition of this project and the development of a Cooperative Research and Development Agreement (CRADA). Mr. Cadogan and Dr. Hallbert were named as the management contacts for the respective organizations, and Mr. Hernandez and Mr. Thomas were names as the project technical leads.

As a follow-up to this meeting, Mr. Hernandez and Mr. Thomas met on September 21, 2016, to develop the scope and initial tasks of the project. These tasks are presented in Section 4 of this report.

\section{PROJECT DEVELOPMENT}

To develop the project, a set of meetings were held in which the scope and schedule of the project was set, and the technical objectives were established.

\subsection{Cooperative Research and Development Agreement (CRADA)}

In November 2015, work began on a Statement of Work based on the scope and task definition that had been agreed upon in the September meetings. In January 2016, the contracts and legal staff of both parties were engaged to consider the CRADA terms and conditions, as well as the proposed project tasks in the Statement of Work. Refinements were made to the Statement of Work and the draft CRADA was put in the INL approval process.

As of this time of this report, the CRADA process is near completion with approval by DOE and Arizona Public Service (APS) expected in the next several weeks.

\subsection{Project Collaborators}

In addition to the main project parties of INL and APS, there will be additional collaborators who have unique expertise and experience in certain aspects of the technology developments. Discussions have been held with each of them to confirm their willingness to participate in the project in the defined roles and within the proposed terms. Existing or new agreements will be used to formally secure their participation in the project.

\subsubsection{Institute for Energy Technology}

The Institute for Energy Technology (IFE), located in Norway, is an international research foundation for energy and nuclear technology. IFE's mandate is to undertake R\&D within the energy and petroleum sector, and to carry out assignments in the field of nuclear technology for the nation. IFE administers the Halden Reactor Project, which is an international research cooperation on reactor safety [1].

The R\&D programs of IFE extends to many aspects of nuclear plant operations; however, the main area of interest to the II\&C Pathway is the man-machine-technology research program that conducts research in the areas of computerized surveillance systems, human factors, and man-machine interaction in support of control room modernization. IFE has assisted a number of European nuclear power plants (NPP) in implementing II\&C modernization projects, including control room upgrades. 
IFEs will be an active research partner in this project, collaborating in the design and development of a proposed control room end-state concept for the PVNGS control room, as well as conducting human factors evaluations of candidate control room technologies and control room configuration options. In addition, IFE will participate in control room design and human factors evaluation sessions with PVNGS staff, drawing on their considerable experience in conducting such nuclear operator workshops for advanced control room technologies.

\subsubsection{Electric Power Research Institute}

The EPRI is the foremost research organization for the U.S. electric power industry, being directly sponsored and supported by the utilities and other industry stakeholders. In the nuclear power area, it works with about $80 \%$ of the nuclear power plants in the world. It is a member of the LWRS Program II\&C Pathway Utility Working Group (UWG) and plays an active role in conducting research for the LWRS pilot projects. Moreover, EPRI has been the sponsor and lead organization in some areas of pilot project research activities.

EPRI has conducted numerous R\&D activities over the past several decades in support of nuclear plant digital implementation and related issues and has made relevant reports and guidelines available to the LWRS Program. The nuclear utilities rely on these reports as the basis of their internal programs and methodologies in implementing digital systems for their plants. A number of these reports have been endorsed by the Nuclear Regulatory Commission in regulatory guidance documents.

EPRI will participate in the development of technologies for this project as a technical advisor, representing both their own relevant research findings as well as general knowledge of nuclear utility requirements. They will provide expert review of project plans, project results, and project reports. In addition, they will assist with utility and industry engagement through their network of utility contacts and sponsored industry meetings.

\subsubsection{Engineering and Human Factors Consultants}

Engineering and human factors consultants will be engaged in the project as needed for expertise and development work. There are several industry-recognized experts in these fields with decades of experience in the notable developments in control room concepts and technologies, including the original control room concepts for the operating nuclear plant, the Advanced Light Water Reactor designs of the 1990s, and the current new-builds employing fully digital control rooms. In addition to technical considerations, these consultants have extensive experience in regulatory issues affecting digital technology and control room human factors.

Project funding has been allocated to engage these experts in appropriate project activities, including their direct participation in development activities as well as their expert review of project plans, project results, and project reports that ensue from the project tasks.

\subsection{Project Facilities/Capabilities}

\subsubsection{Human System Simulation Laboratory}

The HSSL at INL is used to conduct research in the design and evaluation of hybrid control rooms, integration of control room systems, development and piloting of human-centered design activities with operating crews, and visualizations of different end state operational concepts. This advanced facility supports human factors research for operating nuclear plant control rooms, including human-in-the-loop performance and human-system interfaces, and can incorporate mixtures of analog and digital hybrid displays and controls. It is applicable to the development and evaluation of control systems and displays of NPP control rooms, and other command and control systems.

The simulator consists of 15 bench board-style touch panels that respond to touch gestures similar to the control devices in an actual control room (see Figure 1). The simulator is able to run actual LWR 
plant simulation software used for operator training and other purposes. It is reconfigurable in the sense that the simulator can be easily switched to the software and control board images of different LWR plants, thus making it a universal test bed for the LWR fleet.

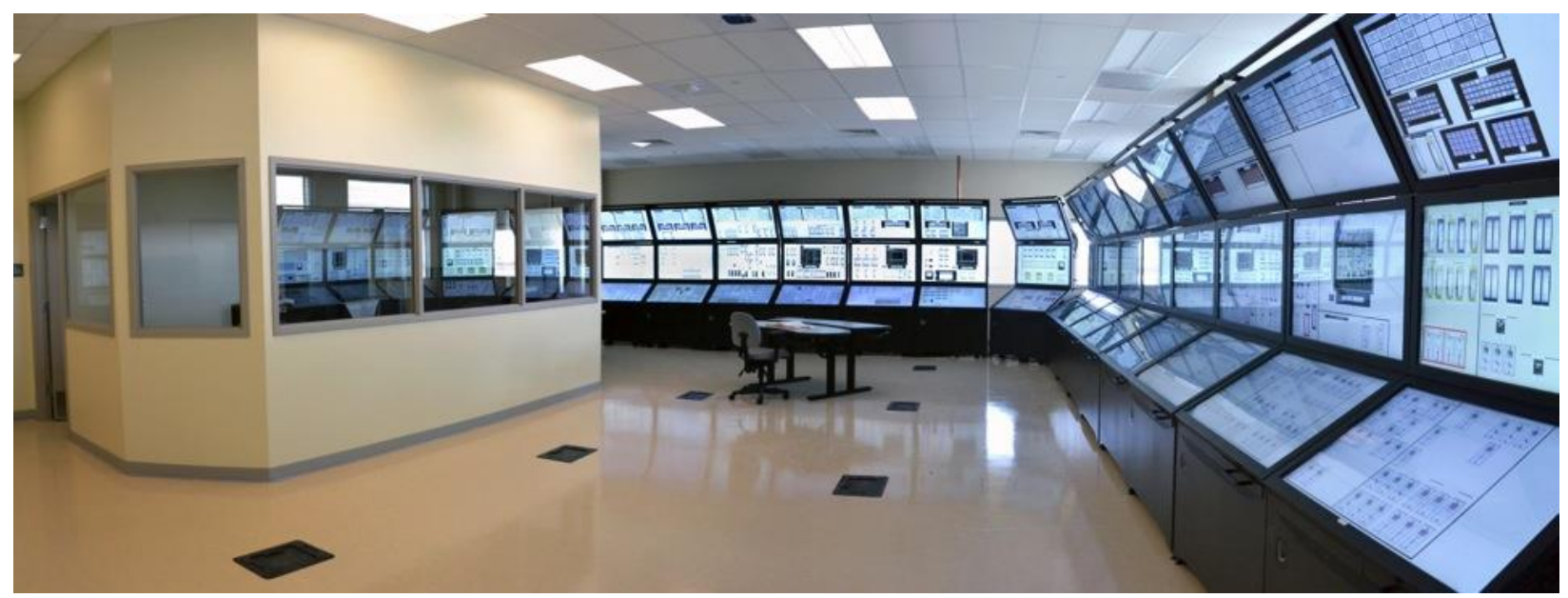

Figure 1. Human Systems Simulation Laboratory - Reconfigurable Hybrid Control Room Simulator.

The HSSL will be used in the project to develop a working simulator model of the end-state concept for PVNGS control room modernization. The simulator will be fully functional, allowing plant operators to validate the design by running standard training scenarios just as they would in the plant's own training simulator. These scenarios will be run with and without the configuration and digital technology changes, enabling a direct comparison of the before and after control room configurations and direct measurement of the expected benefits.

\subsubsection{Three-Dimensional Modeling}

Three-Dimensional (3-D) Modeling software will be used to create accurate models of the baseline and end-state concepts for the PVNGS control room. These models will depict both the physical arrangement of the rooms and control panels, as well as the devices on the control boards. This includes details right down to the size and font of the text on component labels. Because the models will be dimensionally accurate, they can serve as a basis for verifying the human factors principles that apply to control room design. For example, they can verify that text sizes are adequate for viewing by the operators from a prescribed distance.

Using these models, human factors engineering evaluations will be conducted to ensure that the end-state concepts, including interim configurations, conform to human factors requirements, especially those described in Nuclear Regulatory Commission (NRC) review guidance, such as NUREG-0700. Operator figures can be placed in the models to represent the range of human attributes (height, eye sight, reach, peripheral vision, etc.) that are of interest in validating the suitability of the operating environment, as shown in Figure 2.

The 3-D models will also be used in various types of visualization techniques that will provide greater understanding of the end-state concept. These include still views, section and plan views, 3-D tours, and use in a virtual reality environment as described in the next section. The 3-D models will be kept current with the end-state concepts design as they progress in the HSSL so that they can together reflect the current status of the functional and physical aspects of the modernized control room. 


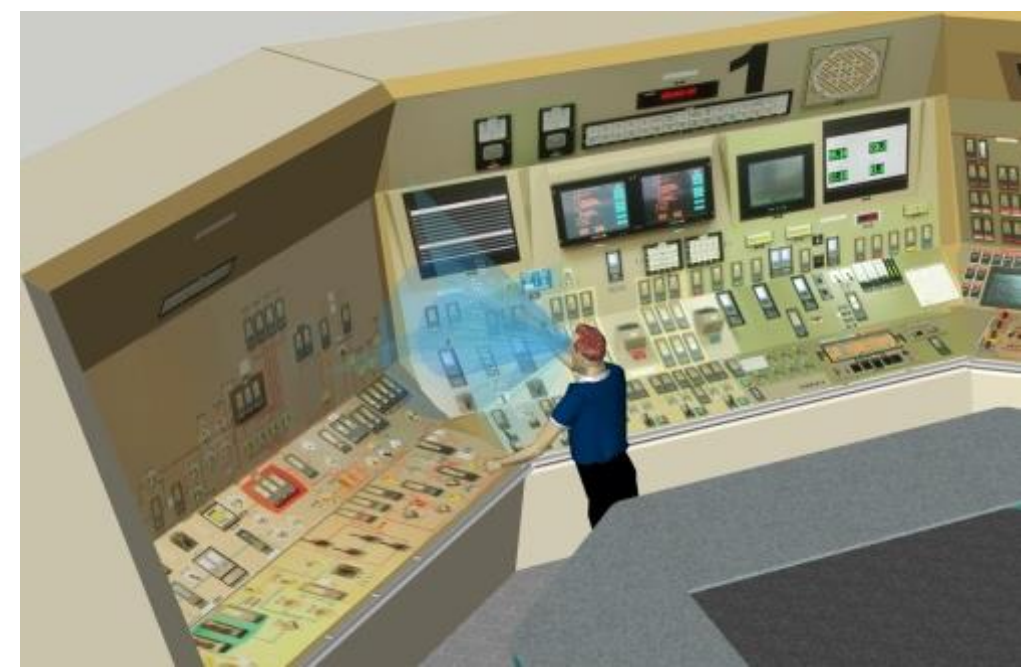

Figure 2. 3-D Control Room Model depicting operator vision attributes.

\subsubsection{Computer Assisted Virtual Environment}

The Computer-Assisted Virtual Environment (CAVE) is a 3-D advanced visualization tool that allows researchers to literally walk into their data and examine it from various angles [2]. Located in the Center for Advanced Energy Studies (CAES), it is part of the Advanced Visualization Laboratory that resembles a cave - black walls, ceiling, and carpet and dim lights to reduce glare. In the middle of the room stand three white walls, each 10 feet wide, and a slightly raised white floor. The projectors mounted are behind the walls and on the ceiling and create the 3-D images. With the help of specialized 3-D goggles and a handheld controller, the user is able to step into the CAVE and manipulate the data. The system is designed to track the movement of the user's head and the controller so the images can react accordingly [2].

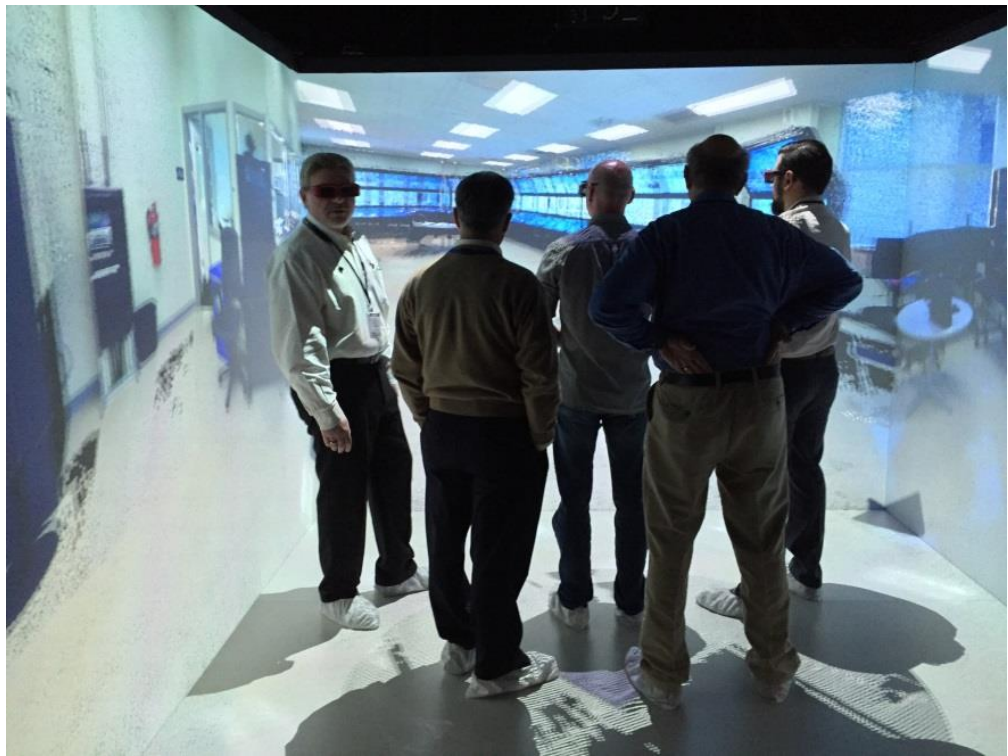

Figure 3. The Computer-Assisted Virtual Environment (CAVE).

The CAVE will be used to create a 3-D projection of the baseline and end-state concepts for the PVNGS control room modernization project. This will include interim stages so plant staff can visualize 
the interim and final configurations of the control room, allowing them to virtually "step into" the end-state concept to gain a realistic sense of what it will be like to be in the modernized control room.

\subsection{Project Development Meetings}

A series of projects meetings were held in mid-January 2016 to introduce the project team members and orient them to the project facilities and capabilities.

\subsubsection{Project Technical Meeting}

A project technical meeting was conducted on January 11-12 at INL to develop initial designs for an End-State Concept for a modernized control room for PVNGS (Figure 4). In addition to the INL project team, a representative from the IFE Halden Reactor Project (Norway) and a representative from EPRI participated. Several options for improving the control room from a human factors perspective were derived from the discussions based on a review of the existing control room configuration as well as consideration of the scope of a series of control system upgrades the station is planning as part of their Strategic Modernization Program (SMP). In addition, human factors engineering methodologies were discussed and selected for inclusion in design and verification tasks to be conducted later in the project.

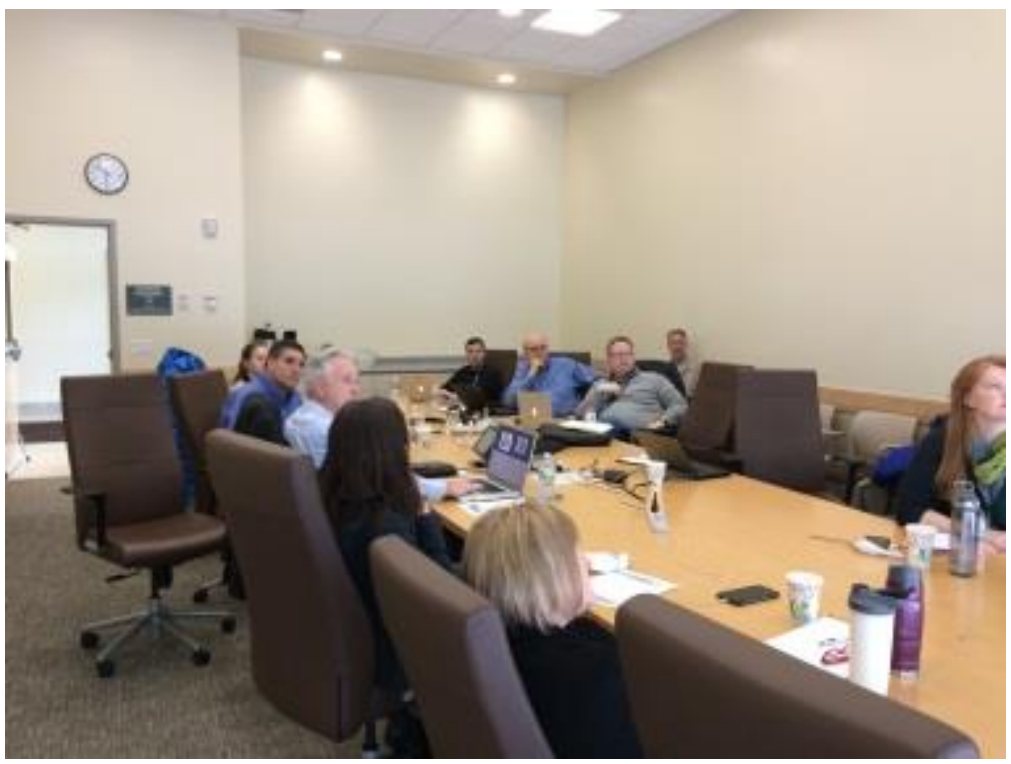

Figure 4. Project technical meeting resulting in initial designs for the End-State Concept.

\subsubsection{Meeting with APS Representatives}

On January 14-15, 2016, representatives of PVNGS joined the project technical meeting for an orientation to the capabilities and facilities of the LWRS Program, demonstration of the DOE HSSL, and a briefing on the initial designs for the End-State Concept (Figure 5). Representing PVNGS were John Hernandez (Project Engineer), Panos Paramithas (Director, Engineering Projects), and Michael Grigsby (Assistant Plant Manager).

Discussions were also held on the scope of the work for the project and what support is required of each of the parties. The Statement of Work for the CRADA was reviewed and modified accordingly. Additional discussions were conducted pertaining to project logistics, upcoming meetings, and support requirements. The role of Westinghouse was explained by the PVNGS representatives (described in Section 3.4.4). Finally, a standing project conference call was set up to provide a monthly opportunity for the parties to review project status, upcoming activities, and support needs. 


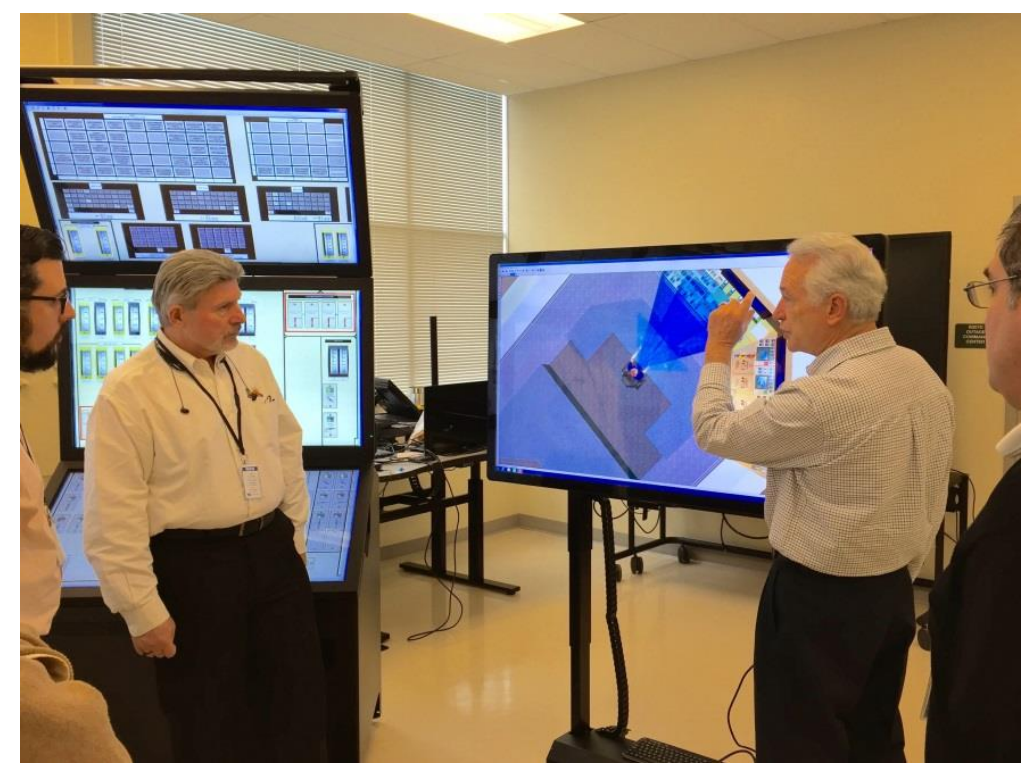

Figure 5. PVNGS representatives participate in a demonstration of project capabilities.

\subsubsection{PVNGS Control Room Survey}

The INL project team, along with the IFE Halden and EPRI collaborators, met January 18, 2016, with the PVNGS Simulator Support organization to conduct walkdowns of the current control room configuration (using their training simulator) to collect data on which control board devices were removed through the planned control system upgrades and the control board space was opened up for improved technology to be integrated into the control room. This walkdown also included a review of human factors issues for the current control room that were addressed in the project. Finally, it included interviews with control room operators to gain their input on opportunities for improving the control room.

The information gained during the control room survey will be used to construct a 3-D model of the control room as part of Task 1 of the project (see Section 4.1), as example of which is shown in Figure 6.

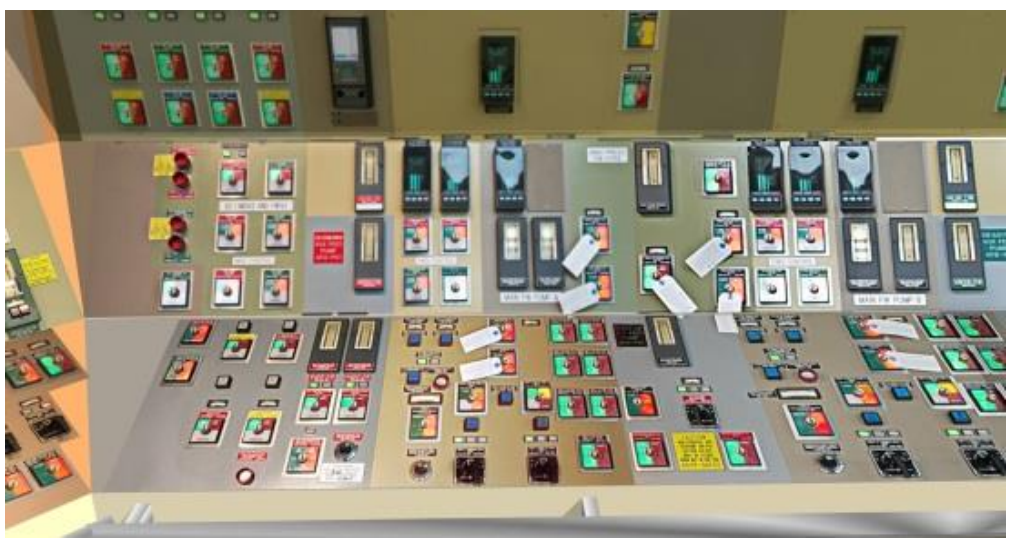

Figure 6. Example of a control board model created from the control room survey data. 


\subsubsection{Meeting with Westinghouse Electric Corporation}

On January 19, 2016, a project management meeting was held with representatives of INL, PVNGS, and Westinghouse Electric Corporation, who is the designated supplier of the control system upgrades. This meeting established the respective roles and responsibilities among the three parties in the development of the End-State Concept, as well as the working relationships and communication channels for the conduct of the project.

\subsubsection{Meeting with STARS Alliance}

STARS Alliance conducts cooperative activities on behalf of four large nuclear stations in the NRC Region V: PVNGS, Callaway, Diablo Canyon, and Wolf Creek Nuclear Stations. STARS Alliance offices are located in Goodyear, Arizona.

At the request of PVNGS management, a meeting was arranged with Mr. Steve Coppock, Executive Director of STARS Alliance. Attending the meeting were John Hernandez of PVNGS, Ken Thomas of INL, Darrell Weber of Westinghouse, and Panfilo Federico of Westinghouse. Westinghouse attended the meeting to represent their role in this project, as well as their overall support role for STARS Alliance member plants.

This meeting provided information to Mr. Coppock on the scope and nature of the FOAK Control Room Modernization Project and opened a discussion with STARS Alliance on similar opportunities with the other members. Mr. Coppock suggested that presentations be given to two specific STARS working groups: Engineering Vice-Presidents and the Operations Peer Team. These groups have monthly phone calls and semi-annual meetings. It would be possible to arrange webcasts at other times.

As a result of the meeting, Mr. Coppock will work with the project technical leads to arrange times for presentations to each of these groups.

\subsubsection{Westinghouse Project Meeting and Project Facilities Orientation}

Mr. Panfilo Federico of Westinghouse visited INL on January 20, 2016, for an orientation and demonstration of the project capabilities and facilities, including the DOE HSSL and the CAVE. Demonstrations were also conducted in how operator performance is measured, including the use of eye tracker technology. In addition, presentations were made to Mr. Federico on other LWRS Program pilot projects that are relevant to the control room modernization pilot project, including computer-based procedures, automated work packages, control room upgrades benefits studies, and wireless component position technologies. The result of these discussions were a shared understanding of how the design and human factors engineering evaluations of proposed changes to the PVNGS control room could be conducted using the facilities and related methodologies and tools.

Specific discussions were also held on the best means of incorporating the Westinghouse OVATION distributed control system upgrades into the PVNGS simulator software once it is installed on the DOE HSSL. Mr. Federico mentioned the possibility of Westinghouse providing images of OVATION display screens for use in the initial control room design activities involving static displays. (Mr. Federico later confirmed that this would be possible.) In addition, preliminary discussions were held on Westinghouse staff participating in design sessions at INL in which control room layout changes would be proposed to accommodate the inclusion of displays for the OVATION system along with other beneficial operator technologies. These sessions will be scheduled as the project progresses.

It was further agreed that a two-way Non-Disclosure Agreement would be pursued between INL and Westinghouse to enable the sharing of proprietary information in either direction. A one-way NDA is still in effect between the companies, which allows INL to receive certain proprietary information of Westinghouse. This NDA was implemented for the acquisition of certain Westinghouse software modules that have relevance to this project; however, it is set to expire in July 2016. Westinghouse legal staff 
requested that this be initially formulated by INL to ensure that all DOE requirements were represented, and this effort is underway.

\section{PROJECT TASKS}

The project consists of five project tasks at present that are designed to take the project to the point where a decision can be made to go forward with an end-state vision for a modernized control room.

\subsection{Task 1: Control Room Baseline Model}

INL will develop a 3-D model of the PVNGS control room, depicting the main control boards as well as any other control stations and plant information displays. The model will include representations of all workstations (board operators, senior reactor operators, shift technical advisor, shift supervisor/manager, etc.) and any other room features. The model will be dimensionally accurate and suitable for conducting human factors and ergonomic studies. In a future project task, the model will be modified to the recommended end-state concept for modernization, so that conformance to human factors principles can be verified.

INL will conduct a limited human factors review of the existing PVNGS control room to identify any significant opportunities to improve the control room layout as part of the recommended control room end-state concept.

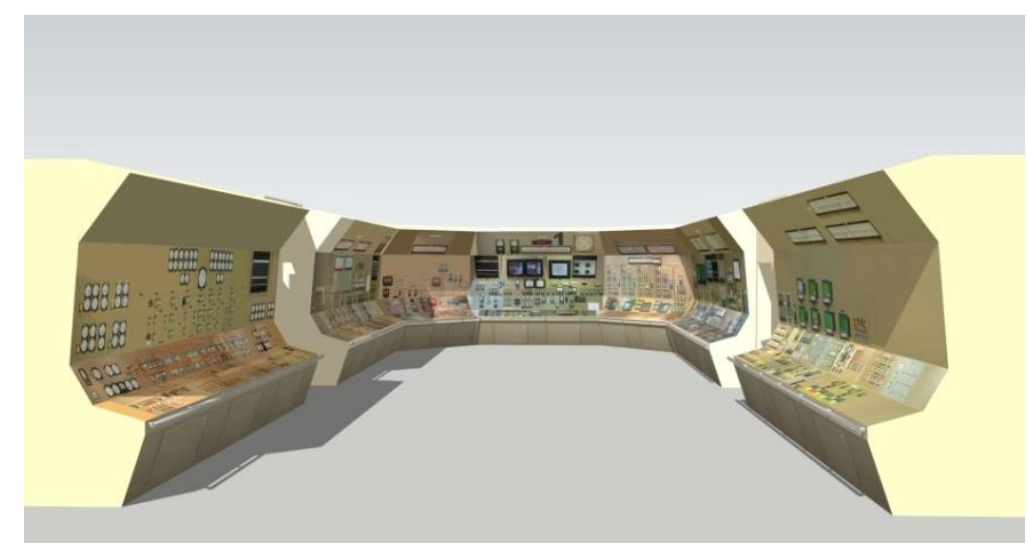

Figure 7. Initial version of a 3-D baseline model of the PVNGS control room.

PVNGS will provide control room general arrangement drawings and panel outline drawings for the main control board, as well as any other needed information to accurately represent the arrangement of the control boards and II\&C components on the contractor's HSSL simulator.

Deliverables:

1. 3-D model of the PVNGS control room

2. Limited human factors review of the existing configuration.

\subsection{Task 2: End-State Concept for a Modernized Control Room}

An end-state concept for a modernized control room for PVNGS, reflecting a series of II\&C digital upgrades PVNGS may pursue over the next 10 or more years. The end-state concept will reflect options for human factors improvement of the control room arrangement and the deployment of new digital technologies for operator performance improvement. The development work will be conducted in the HSSL resulting in a working simulator model of the proposed end-state concept for the control room.

In collaboration with PVNGS's engineering and operations staff, a preliminary end-state concept will be developed first and displayed statically in the HSSL. This will be used to conduct evaluation 
processes, including an operator study, to determine the suitability of the design to improve operator performance and provide substantial operational efficiencies. Scientifically collected data will be analyzed to determine the magnitude of the benefits as input to a business case to be developed in a future project task. This analysis, along with the feedback from the operator studies, will be used to refine the preliminary end-state concept, resulting in the final end-state concept.

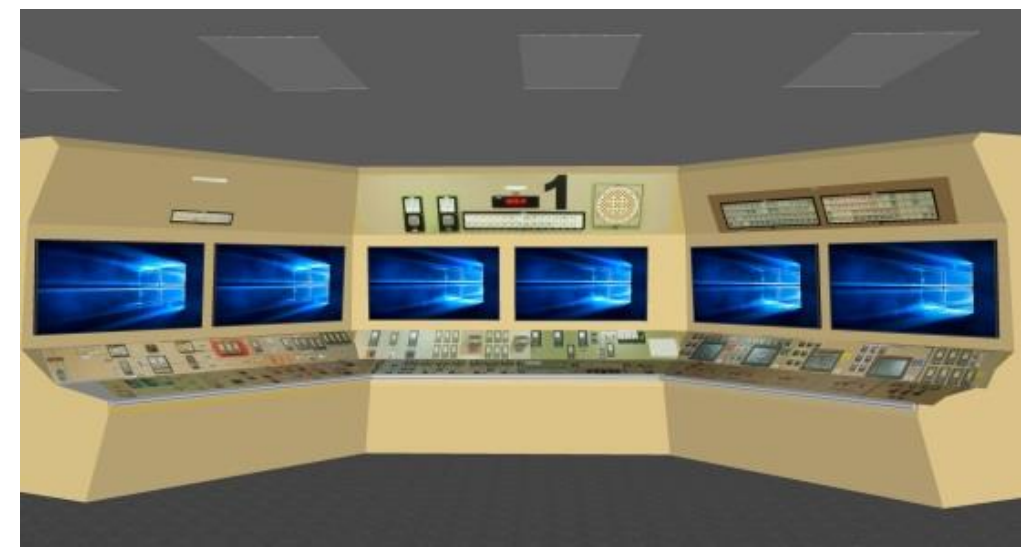

Figure 8. Depiction of possible location of digital displays in the PVNGS control room.

INL will conduct all development and evaluation processes leading to the final end-state concept. This will result in published reports on both the preliminary and final end-state concepts.

PVNGS participant will provide needed information on the current configuration of the control room, conduct of operations information such as operator procedures, control room protocols, operator performance information, and control room operating experience. PVNGS will provide control room operators to participate in the HSSL operator studies. In addition, PVNGS will provide information and access to key engineering and operations personnel for consultation on the possible II\&C upgrades.

Deliverables:

1. Preliminary end-state concept

2. Final end-state concept.

\subsection{Task 3: Style Guide}

The purpose of the style guide is to ensure consistency with the conventions that are adopted for the end-state concept for the control room. The contractor will provide a style guide for possible II\&C upgrades, as well as for consideration in any opportunities to make existing control room displays and devices conform to the selected conventions. The style guide will describe a uniform set of standards for control board devices such as displays, labeling, use of colors, font types and sizes, etc. Contractor will work with the PVNGS engineering and operations staff, as well as the supplier of the II\&C system upgrades, to optimize the various parameters of the style guide, taking into account current standards for control board style parameters, as well as the existing control board style implementation.

Deliverables:

1. PVNGS Control Room Style Guide.

\subsection{Task 4: Modernized Control Room Business Case Framework}

INL will develop a framework for a PVNGS Control Room Modernization Business Case that will describe the major areas of benefit that can be expected from the implementation of the end-state concept. The business case will include direct savings in terms of work efficiencies and reduced staffing, where 
possible and consistent with staffing commitments. These work efficiencies will stem from control room activities, interface with field operational activities, and interface with station support processes. The business case will credit savings related to generation losses and regulatory impacts where it can be demonstrated that improved control room technology would preclude historical-based events and transients. It will include savings from reduced administrative burden and paper costs. It will credit certain aspects of outage performance due to improved operations support.

The business case will also include indirect benefits in key performance indicators and other important measures. These would include reduced safety challenges, reduced technical specification entries, improved safety system unavailability, improved adherence to operational expectations, reduced operator workarounds, reduced misposition events, and reduced control room deficiencies.

It should be noted that a complete business case with break-even analysis will not be possible at this stage of the project because the implementation costs will not be known. Also, at this point in the project, only a rough order of magnitude of the savings can be determined. However, the analysis at this point in the project should be sufficient to support decision making on whether to proceed with the design phase of the end-state concept. A later project task will develop a more complete business case.

PVNGS will provide current and historic data on related performance issues as baseline data for the business case framework.

Deliverables:

1. Business Case Framework Report.

\subsection{Task 5: Industry Engagement}

INL will conduct certain industry and regulatory engagement activities to ensure that appropriate technical and business case expertise is applied to the project so that the results are of the highest value to the participant. This will also ensure that they are generally applicable to the U.S. nuclear power industry as a whole. There will be engagement with the major nuclear industry support groups to ensure that the results are in line with industry standards and best practices.

Subject to all proprietary information and intellectual property provisions in the agreement, PVNGS will make mutually agreeable project material and background information available for these purposes. In addition, PVNGS will participate in technical meetings, web meetings, and conference calls to a reasonable extent to represent the utility viewpoint and experience in the project.

By express permission of the participant and subject to the provisions in this CRADA, INL will use representations of the PVNGS control room, depicting the current configuration and the end-state concept, as well as other appropriate project materials, for the purposes of representing this project and related findings to nuclear utilities and other nuclear industry stakeholders.

Deliverables:

1. Papers and presentations representing certain aspects of the conduct of this project and the resulting findings, as appropriate opportunities are available.

2. Demonstrations to various approved audiences of project developments in the HSSL and other DOE demonstration facilities.

\section{PROJECT DELIVERABLES}

Milestone deliverables have been defined for each of the project tasks and are presented in Table 1 below. In addition, other deliverable products will likely be defined during the course of the project tasks and added to the project plan. It is anticipated that additional tasks will be added to the project scope based on success in the initial tasks, and deliverable products for these tasks will be added as well. 
Table 1. Milestone deliverables.

\begin{tabular}{|c|l|c|}
\hline $\begin{array}{c}\text { Task } \\
\text { No. }\end{array}$ & \multicolumn{1}{|c|}{ Project Deliverables } & Due Date \\
\hline 1 & $\begin{array}{l}\text { 3-D Model of the PVNGS control room. } \\
\text { Limited human factors review of the existing configuration. }\end{array}$ & April 29, 2016 \\
\hline 2 & Preliminary end-state Concept for the PVNGS Control Room & April 29, 2016 \\
\hline 2 & Final End-State Concept for the PVNGS Control Room & September 30, 2016 \\
\hline 3 & PVNGS Control Room Style Guide & December 31, 2016 \\
\hline 4 & $\begin{array}{l}\text { End-State Concept Business Case Framework } \\
\text { Papers and presentations representing certain aspects of the conduct of } \\
\text { this project and the resulting findings, as appropriate opportunities are } \\
\text { available. } \\
\text { Demonstrations to various approved audiences of project } \\
\text { developments in the HSSL and other DOE demonstration facilities. }\end{array}$ & $\begin{array}{c}\text { Duration of the } \\
\text { Project }\end{array}$ \\
\hline
\end{tabular}

\section{SUMMARY}

This project plan describes a comprehensive approach to the design of an end-state concept for a modernized control room for PVNGS to assist this first-mover nuclear utility in addressing legacy analog technology issues of reliability, obsolescence, as well as to enable improved operator and plant performance. This project will also demonstrate the feasibility and benefits of control room modernization to the commercial nuclear operators, suppliers, and industry support community. It will be a major step in resolving legacy II\&C issues that potentially impact long-term sustainability of the LWR fleet.

This project applies advanced tools, methodologies, and facilities in a science-based approach to the validation of engineering and human factors principles for nuclear plant control room modernization. It addresses the required project results and documentation to demonstrate compliance with regulatory requirements.

This project plan describes the collaboration arrangement between the LWRS program and the APS Palo Verde Nuclear Generating Station. It also describes the role of other collaborators, including the IFE and the EPRI. Finally, it describes the project tasks that will be conducted in the project, and the deliverable reports that will be developed through these tasks.

This project plan will be updated as new tasks are added and as project milestones are completed. It will serve as an ongoing description on the project both for project participants and for industry stakeholders.

\section{REFERENCES}

1. Institute for Energy Technology, http://www.ife.no/en, Web page accessed February 2016.

2. Phys Org, "New perspective in the CAVE with 3-D computer-assisted virtual environment," http://phys.org/news/2010-10-perspective-cave-d-computer-assisted-virtual.html, October 19, 2010, Web page accessed February 2016. 